\title{
Determinants of consumers' choice behaviour for fresh fish types
}

\section{Sina Basil Johnson ${ }^{1 *}$; Ojuotimi Enitan Mafimisebi²; Joseph Olubukun Ikuerowo $^{3}$; Orimisan Justin Ijigbade ${ }^{4}$}

1),2) Department of Agricultural Extension \& Management, Rufus Giwa Polytechnic, Owo, Nigeria

3) Department of Agricultural Economics \& Extension, Olusegun Agagu University of Science \& Technology, Okitipupa, Nigeria

4) Department of Agricultural Technology, Rufus Giwa Polytechnic, Owo, Nigeria

*To whom correspondence should be addressed. Email: johnsonbasil95@yahoo.com

\begin{tabular}{|l|l|l|l|l|}
\hline DOI: & Received: & Revised: & Accepted: & Published: \\
10.22437/ppd.v8i3.9512 & 04.06 .2020 & 28.07 .2020 & 02.08 .2020 & 31.08 .2020 \\
\hline
\end{tabular}

\begin{abstract}
The demand for and supply of fresh fish in many developing countries in the world today Nigeria inclusive, are yet to satisfy the annual dietary needs of their citizenry. This phenomenon, therefore, put unresisting pressure on the need to identify and grow more fresh fish that can meet the socio-cultural and economic desires of consumers. In the light of this, the present study examines the determinants of consumers' choice behaviour for fresh fish types in Nigeria. Primary data were collected from 360 household heads through a structured questionnaire using a multistage sampling procedure. Multinomial logit regression model (MNL) was employed to analyse the impacts of socio-economic and fish-specific attributes of consumer choice for fresh fish. Results showed that 81 per cent were female households with a mean age of 35 years and mean household size of 4 members. Mean years of schooling and monthly expenditure were 13 and $\$ 3,611.94$ (USD10.01), respectively. Mean consumptions of fresh fish category were mudfish (0.3354), catfish (0.1889), tilapia (0.2167), trunk fish (0.1138) and snakehead fish (0.1444). The McFadden $\mathrm{R}^{2}$ was 0.50 and the validity of independence of irrelevant alternatives hypothesis for the use of MNL was not violated given a p-value of 0.7618. Results showed that consumers' income, price of the fish, level of education, household size, experience and freshness had a significant impact on fresh fish choices. The study therefore recommends that policy that will increase consumers' satisfaction for every naira spent on fresh fish and improve fish qualities should be given proper attentions.
\end{abstract}

Keywords: Consumer behaviour, Fish, Multinomial logit, Nigeria

JEL Classification: C5, D11, B23, Q22

\section{INTRODUCTION}

Fishery is a strategic subsector in Nigeria, contributing immensely to the food security of the country. It employs over 8.6 million people directly and 19.6 million indirectly (World Fish, 2018). Nigerian fishing activities are made up of three sources such as artisanal, industrial and aquaculture. Fishery sector provides over 40 per cent of 
the total protein-intake in the country and contributes about $0.5 \%$ to the national gross domestic product in 2015 (Food and Agriculture Organization [FAO], 2007). Nigeria requires about 2.7 million metric tons of fish annually to satisfy the dietary needs of its citizens. However, the aggregate total domestic fish supply from all sources, both from capture and culture fisheries, is about 0.8 million metric tons per annum thereby creating a deficit of 1.9 million tons to fill the demand-supply gap (Emefiele, 2019). Consequently, over $\$ 1.2$ billion is being spent on the importation of frozen fish annually to bridge this gap (FAO, 2007). Available information revealed that only 30 percent of the fish consume in Nigeria can be produced domestically while the remaining 70 percent is being imported. Meanwhile, Nigeria is the largest importer of frozen fish in Africa. This has serious implications for the Nigerian population of about 195 million with 2.6 percent annual growth rate (World Bank, 2018). The country has a comparative advantage of producing fresh fish abundantly for both local consumptions and export the surplus. This is premised on the fact that it has a coastline of $853 \mathrm{~km}$ (Central Intelligence Agency [CIA], 2014) couple with 200 nautical miles of Exclusive Economic Zone.

For more than 35 years, Nigeria aquaculture grows by about 12 per cent a year compare to the World average of 8 per cent from over 6,000 metric ton in 1980 to about 307,000 tons in 2016 (World Fish, 2018). Nigeria is the largest aquaculture fish producer in sub-Sahara Africa, accounting for 52 per cent of the total fish farmed in the region (World Fish, 2018). The country's aquaculture focuses on freshwater fish, with catfish as major species. Despite the availability of water and human resources in the country, the demand for fish continues to exceed its domestic production annually. In Nigeria, per capita consumption of $13.3 \mathrm{~kg} /$ person of fish are still relatively low compared with the global average of $20.0 \mathrm{~kg}$ (FAO, 2007).

Notwithstanding a number of economic literatures have made us to know that socio-economic and product-specific variables have significant influences on consumers' preferences for a product in behavioural studies, relatively few have assessed the impacts of these factors on consumers' choice behaviour for fresh fish types especially in the study area. A number of studies reviewed show that gap exists in the study area. For instance, Qiujie et al. (2018) investigated factors influencing consumers' purchase intentions for sustainable wild salmon in the Chinese market and implications for agribusiness decisions using ordered logit model. The result of their study showed that education, household size, increase in income over the last two years, dummy for Shanghai city, harvest methods, tasty, cleanliness, dinning venue (i.e. eat salmon at home, restaurants and both) had a positive and significant influence on consumers' purchase intentions while factors like preservation by frozen, place of eating salmon other than home and restaurants had negative but significant impact on the consumers' intention for wild salmon in the study area. The authors also modeled factors influencing consumers' intentions for purchasing wild salmon heads and bones from Alaska. The result was that consumers with college education, method of harvesting of salmon, dinning venue such as home and restaurant, cleanliness and nutritious were all have positive significant impacts on consumer' intention to buy heads and bones of wild salmon. However, consumer' annual income, preservation with water, preservation by frozen, and other places where wild salmon could be obtained for consumption were negatively signed but had significant relationship with consumers' intention to purchase heads/bones of wild salmon. The study therefore concluded that factors such as consumers' perception on the food safety, sustainability of production environment and taste played a significant role in purchase intentions for wild salmon 
fillet while positive perception of the production environment and nutritious induced consumers to have more purchasing intention for wild salmon heads/bones.

Azabagaoglu et al. (2016)'s study was conducted on consumer's fish purchase behavior in Tekirdag in Turkey using best-worst analysis. The study found that the major reason for consuming fish in the study area was because of its healthiness while the reason for not buying fish was identified as difficulty associated with fish preparation. Nauman et al. (1995) employed logit regression model based on a modified evoked set framework to examine the effects experience, perceptions and preferences have on the decision of consumers to purchase fresh hybrid striped bass, trout and salmon in Northeastern USA. Results of the study reported that production environment, experience on seafood purchases, .healthiness and taste had a positive and significant impacts on consumer decision to buy fresh finfish.

The study by Adeola et al. (2016) focused on marketing perspective of smoked catfish in Southwest, Nigeria using Tobit model to analyze field survey. The study identified consumer's income and household size as factors that had positive influence on catfish consumption. Bonface et al. (2017) employed Almost Ideal Demand System and multivariate probit model to analyze the demand for fish products in Malawi. The study concluded that socioeconomic variables were significantly related to fish demand while Kreider et al. (1993) analysed consumer perceptions of fresh fish and seafood in the Delmarva region using chi-square of independence. The study identified freshness, a good appearance, flavour and safety as factors influencing consumers in purchasing fresh fish and seafood while taste, odour and price were the major factors preventing consumers from purchases seafood. George et al. (2017) used choice experiment to examine households' willingness to pay for fish product attributes and implications for market feasibility of wastewater-based aquaculture businesses in Hanoi, Vietnam. The study reported that household decision to purchase fish was influenced by access to information on fish attributes to know if waste water was used to rear fish, certification, age, income and household size. Similarly, Jimoh et al. (2013) evaluated consumers' preference for fresh and frozen fish products in Ibadan metropolis, Nigeria. The decision to purchase fresh and frozen fish is influenced by education, occupation, family expenses, taste, package, cost and availability of the fish. Ratliff (2017) investigated factors influencing consumer preferences for tangible and intangible seafood characteristics and community supported fishery marketing outlets in South Carolina using ordered probit and multinomial logit models. Results of the study indicated that demographic characteristics and lifestyle have significant impact on both tangible and intangible seafood characteristics. Moses et al. (2015) investigated socio-economic characteristics influence on consumers' preference on fish purchase in Yola North Local Government Area of Adamawa State, Nigeria using multiple regressions. The study concluded that consumer' preferences were positively influenced by age, education, income and household size of the respondents while Can et al. (2015) in Turkey found out that number of fish species consumed and age of respondent are factors influencing fish consumption. The study used multiple regressions to predict factors affecting fish consumption in their study area.

From the foregoing, studies on consumers' choice behavior for fresh fish are still relatively scarce, thus posing a serious challenge to the formulation of appropriate policy in the study area. Previous studies focused on smoked and frozen fish without adequate consideration to look at the factors affecting the choice of consumers for fresh fish types. These inadequacies create a gap for this study to fill. This study is therefore considered to gain more insight into the influence of socioeconomic variables and fish 
specific-attributes of consumers' choice behaviour for fresh fish types in Nigeria. Specifically, the study described the socioeconomic characteristics of consumers and identified factors affecting the choice of consumers for fresh fish type (The following fish were selected based on their consumption frequency- catfish, mudfish, tilapia, trunk fish and snake head). Therefore the results from this study are expected to provide relevant information for policy makers, captains of industries and researchers.

\section{THEORETICAL MODEL}

The concept employs in this study is built in general, on random utility theory with the assumption that every consumer is a rational decision maker. Utility is a benefit an individual $n$ could derive from choosing an alternative $i$. Every individual is assumed to be rational relative to his choices. Considering an individual $n$ making a decision involving an exclusive alternative that constituted a choice set $\left(C_{n}\right)$ of fresh fish types in our own case, the choice set may vary depending on the household. The selection of fresh fish type $i$ by an individual $n$ from his/her choice set is based on perceived utility $U_{i n}$ of the choice. The utility maximizing behaviour of the consumer is that the consumer $n$ chooses fresh fish type $i$ if, $U_{n i}>U_{n j} \quad \forall_{j} \neq i$

where, $\mathrm{U}_{\mathrm{ni}}$ is the utility of individual $\mathrm{n}$ choosing option $\mathrm{i}$

$\mathrm{U}_{\mathrm{ij}}=$ is the utility of individual $n$ for choosing alternative $\mathrm{j}$

But let us consider a researcher who is investigating consumer choice. The choice of the consumer depends on many factors. Some of the factors are observable and some are not observable. This utility decomposes into various components that depend on factors that fall within the model and factors outside the model but can influence consumer choice. The linear form of this model can be written as

$U_{n i}=\beta \pi_{n i}+\varepsilon_{n i}$

We can deduce equation (3) from 2 as

$$
\pi_{n i}=\pi\left(X_{n i}, S_{n}\right)
$$

From equation (3), $\pi_{\mathrm{ni}}=$ a vector of observed variables relating to alternative $i$ for individual household that depends on the attributes of the alternative, $\mathrm{X}_{\mathrm{ni}}=$ vectors of attributes describing interaction between alternatives $i$ and $j$, respectively. $\mathrm{S}_{\mathrm{n}}=$ vector of individual characteristics that influence his/her choice. $\beta=$ is the vector of the coefficient of observed variables while $\varepsilon_{n i}=$ vector of random component that captures the effects of all unobserved variables that affect individual choice Bateman et al. (2002) and recently cited in (Owusu-Sekyere, 2014).

The conditional probability of his choice then becomes.

$P\left(i / C_{n}\right)=P_{r}\left(\bigcap_{j \neq i} \beta \pi_{n i}+\varepsilon_{n i}>\beta \pi_{n j}+\varepsilon_{n j}\right)=P\left(\bigcap_{j \neq i} \varepsilon_{n j}-\varepsilon_{n i}<\beta \pi_{n i}-\beta \pi_{n j}, \ldots \ldots\right.$.

Given $\beta$, the choice probability is the probability that $\varepsilon_{\mathrm{ni}}-\varepsilon_{\mathrm{nj}}$ are below the respective quantities $\forall_{\mathrm{i} \neq \mathrm{i}}: \beta \pi_{n \mathrm{i}}-\beta \pi_{n \mathrm{j}}$. Different choice models depend on the assumption about the distribution of error term for all $i$ and different treatment of $\beta$. In this study, we assume that our random components for multinomial logit specification are identically and independently distributed across the error terms, (i.e the error terms follow Gumbel distribution).

\section{METHODS}

The study was carried out in Ondo State, Nigeria. The state is bounded in the west by Osun and Ogun States and in the north by Ekiti and Kogi States. Ondo State shares 
boundaries with Edo and Delta States in the east and in the south by the Atlantic Ocean. Ondo State lies between Latitudes $5^{\circ} 45^{\prime}$ and $8^{\circ} 15^{\prime}$ north of the equator and Longitude $4^{\circ} 30^{\prime}$ and $6^{\circ} 60^{\prime}$ east of the Greenwich Meridian. Ondo State has eighteen (18) Local Government Areas with an estimated population of about 3.4 million inhabitants (National Population Commission [NPC], 2006). There are two distinct seasons which are the rainy season (April to October) and the dry season (November to March). Though, there is usually an August break for a period of two weeks. The annual rainfall varies from $1,150 \mathrm{~mm}$ to $2,000 \mathrm{~mm}$. Ondo State riverine area is a veritable ground for fishing.

Primary data used in this study were collected from the household heads using a structured questionnaire. A multi stage sampling procedure was employed to select respondents. The first stage involved the purposive selection of Akure-south and Owo Local Government Areas because of high population of households in the areas. In the second stage, five communities were purposively selected for convenient administration of questionnaire from each of the LGA. In the third stage, 36 respondents were randomly selected from each of the five communities earlier selected in each local government areas thereby giving a total of 360 respondents used in this study.

\section{Data estimation}

This study used tables, mean and standard deviation to summarize the socioeconomic characteristics of the respondents and inferential statistics such as multinomial logit regression to identify factors determining the choice of consumers for fresh fish types.

\section{Multinomial logit regression model}

Following Greene (2003); multinomial logit regression model (MNL) is the standard method for estimating unordered, multi-class or polytomous dependent variables. When there are more than two alternatives, the preferred model is MNL. The choice of consumers' preference $\mathrm{j}^{\text {th }}$ is drawn from the $\mathrm{J}^{\text {th }}$ fresh fish types using a probability set. Therefore, MNL was used in this study to identify factors affecting the choice of consumers for fresh fish types in the study area. One of the categorical variables was set as a reference category. Several researchers have used this model to analyse choice of products or techniques. Multinomial logit regression model is expressed as:

$$
\frac{P(Y=j / X)}{P(Y=J / X)}=\exp ^{\left(\beta_{0}+\sum_{j-1}^{J} \beta_{j} X_{j i}\right)}
$$

The marginal effects were computed to capture the effect of independent variable on dependent variables. This is because the $P(Y=j / X)$ must sum to one. It is therefore easy to establish that:

$\mathrm{P}(\mathrm{Yi}=\mathrm{j} / \mathrm{Xi})=\frac{\exp ^{\beta_{\mathrm{j}} \mathrm{x}_{\mathrm{ji}}}}{1+\sum_{\mathrm{J}=1}^{\mathrm{J}} \exp ^{\beta_{\mathrm{j}} \mathrm{X}_{\mathrm{ji}}}}$

By setting $\beta^{1}=0$, the equations become

$$
\begin{aligned}
& \mathrm{P}\left(\mathrm{Y}_{\mathrm{i}}=1\right)=\frac{1}{1+\mathrm{e}^{\mathrm{X} \beta(2)}+\mathrm{e}^{\mathrm{X} \beta^{(3)}}+\mathrm{e}^{\mathrm{X} \beta^{(4)}}+\mathrm{e}^{\mathrm{X} \beta^{(5)}}} . \\
& \mathrm{P}\left(\mathrm{Y}_{\mathrm{i}}=2\right)=\frac{\mathrm{exp}^{\beta^{(2)}}}{1+\mathrm{e}^{\mathrm{X} \beta^{(2)}}+\mathrm{e}^{\mathrm{X} \beta^{(3)}}+\mathrm{e}^{\mathrm{X} \beta^{(4)}}+\mathrm{e}^{\mathrm{X} \beta^{(5)}}} . \\
& \mathrm{P}\left(\mathrm{Y}_{\mathrm{i}}=3\right)=\frac{\exp ^{\beta^{(3)}}}{1+\mathrm{e}^{\mathrm{X} \beta^{(2)}}+\mathrm{e}^{\mathrm{X} \beta^{(3)}}+\mathrm{e}^{\mathrm{X} \beta^{(4)}}+\mathrm{e}^{\mathrm{X} \beta^{(5)}}}
\end{aligned}
$$




$$
\begin{aligned}
& \mathrm{P}\left(\mathrm{Y}_{\mathrm{i}}=4\right)=\frac{\exp ^{\beta^{(4)}}}{1+\mathrm{e}^{\mathrm{X} \beta^{(2)}}+\mathrm{e}^{\mathrm{X} \beta^{(3)}}+\mathrm{e}^{\mathrm{X} \beta^{(4)}}+\mathrm{e}^{\mathrm{X} \beta^{(5)}}} \\
& \mathrm{P}\left(\mathrm{Y}_{\mathrm{i}}=5\right)=\frac{\exp ^{\beta^{(5)}}}{1+\mathrm{e}^{\mathrm{X} \beta^{(2)}}+\mathrm{e}^{\mathrm{X} \beta^{(3)}}+\mathrm{e}^{\mathrm{X} \beta^{(4)}}+\mathrm{e}^{\mathrm{X} \beta^{(5)}}}
\end{aligned}
$$

Where,

From equation 5, Y $=$ Mudfish $=1$ catfish $=2$, tilapia $=3$, trunk fish $=4$, snakehead $=5$

$\mathrm{X}=$ set of row vector of explanatory variables,

$\beta_{\mathrm{j}}=$ parameters to be estimated $(\mathrm{j}=1,2,3 \ldots \mathrm{J})$, and

$\beta_{0}=$ intercept. The parameters of these equations were estimated through the method of maximum likelihood estimation using STATA version 14.

\section{Socio-economic characteristics of fresh fish consumers}

Table 1 presents the descriptive statistics of consumers and fresh fish-specific attributes in the study area. Most (81 percent) of the respondents were female households with about 73 percent of the households were married which implies that the married buy more fresh fish than unmarried. The result is similar to the earlier study conducted by Solomie et al. (2015) that women were the primary food shoppers in most households. The mean age of respondents was 35 years with a mean household size of 4 members while the mean educational status was 13 years which implies that consumers in the study area have adequate knowledge and awareness to process information about fish attributes.

\begin{tabular}{|c|c|c|c|}
\hline Description & Variable & Mean & Std. dev. \\
\hline FRESH FISH TYPE & - & 2.541 & 1.421 \\
\hline FF_TYPE $=5$ & SNAKEHEAD & 0.144 & 0.352 \\
\hline FF_TYPE $=4$ & TRUNKFISH & 0.113 & 0.318 \\
\hline FF_TYPE $=3$ & TILAPIA & 0.216 & 0.413 \\
\hline FF_TYPE $=2$ & CATFISH & 0.188 & 0.392 \\
\hline FF_TYPE $=1$ & MUDFISH & 0.335 & 0.473 \\
\hline If female $=1,0$ otherwise & D_GENDER & 0.805 & 0.396 \\
\hline If married $=1,0$ otherwise & D_MAR STATUS & 1.733 & 0.443 \\
\hline Number of years spent in schooling & EDUCATION & 13.7166 & 3.409 \\
\hline Number of persons living under the same roof & HHSIZE & 4.4944 & 2.218 \\
\hline Years since birth & AGE & 34.9167 & 10.013 \\
\hline Years of experience in consumption of fresh fish & EXPERIENCE & 25.0806 & 9.433 \\
\hline Having a good taste $=1,0$ otherwise & D_TASTE & 0.655 & 0.476 \\
\hline $\begin{array}{l}\text { If health is the condition for purchase yes }=1,0 \\
\text { otherwise }\end{array}$ & D_HEALTHINESS & 0.255 & 0.437 \\
\hline $\begin{array}{l}\text { If freshness of the fish attract consumer to purchase } \\
\text { yes }=1,0 \text { otherwise }\end{array}$ & D_FRESHNESS & 0.416 & 0.194 \\
\hline $\begin{array}{l}\text { If plenty fish meat is the consideration for purchase } \\
\text { yes }=1,0 \text { otherwise }\end{array}$ & D_FLESHINESS & 0.85 & 0.358 \\
\hline If odour discourages purchases yes $=1,0$ otherwise & D_ODOUR & 0.561 & 0.497 \\
\hline Having little bone in the body: yes $=1,0$ otherwise & D_BONE & 0.672 & 0.47 \\
\hline If it is easy to prepare yes $=1,0$ otherwise & D_EASE PREP & 0.738 & 0.44 \\
\hline $\begin{array}{l}\text { Market price of all fishes considered in the study } \\
N G N(N) / \mathrm{kg}\end{array}$ & PRICE PER FISH & 710 & 154.108 \\
\hline The monthly disposable income (N) & HHINCOME & $75,631.42$ & 68602.82 \\
\hline $\begin{array}{l}\text { Average household expenditure on fresh fish per } \\
\text { month }\end{array}$ & EXPENDITURE & 3611.94 & 2905.51 \\
\hline
\end{tabular}

Table 1. Summary statistics of the variables and fresh fish types

*note price, expenditure and income are expressed in Nigeria currency \$1=N361

Source: Field survey, 2019 
Result showed that majority of the consumers sampled were married, 73 percent of the sampled attributed choice to a simple preparation of fresh fish. The study showed that 66 percent made their choice on the basis of the taste of the fish, 56 percent did not buy because of fish odour, 26.0 percent of the respondents based choice decision on the provision of good health deriving from eating fresh fish while 42 percent of the consumers considered freshness of the fish as a pre-condition to purchase fish. Many (85 percent) consumers preferred to purchase fleshy fish while consumers eat fresh fish if it contains less bone (67 percent) and 74 percent purchase fresh fish if it is easy to prepare. The study revealed that the average price of fresh fishes was $\$ 710.0$ (US\$1.97) while the monthly mean expenditure on fresh fish was $\$ 3,611.94$ (US\$10.12).

\section{RESULTS AND DISCUSSION}

\section{Marginal effects of multinomial logit model}

The coefficients of multinomial logit regression are displayed in Table 2. The estimated coefficient can only show the direction of variables but the magnitude of the effect on the response variables can be given by taking the derivatives of the response variables with respect to individual factor. Therefore, this study discusses the marginal effect of multinomial logit regression to identify factors influencing choice of fresh fish consumed in the study area.

Table 2. Parameter estimates of multinomial logit regression for fresh fish types

\begin{tabular}{lrrrr}
\hline Model & $\begin{array}{r}\text { Catfish } \\
\text { Coeff,(Std.err) }\end{array}$ & $\begin{array}{r}\text { Tilapia fish } \\
\text { Coeff(Std.err) }\end{array}$ & $\begin{array}{r}\text { Trunk fish } \\
\text { Coeff.(Std.err) }\end{array}$ & $\begin{array}{r}\text { Snakehead fish } \\
\text { Coeff.(Std.err) }\end{array}$ \\
\hline CONSTANT & $-393.6746(146.8571)^{* * *}$ & $-1053.611(189.2904)$ & $1032.3089(220.7750)$ & $-1686.24(300.6990)$ \\
D_GENDER & $-0.6726(0.4695)$ & $-0.6673(0.5803$ & $0.229214(0.7318)$ & $-1.0385(1.0286)$ \\
D_MAR STAT & $0.6389(0.5370)$ & $0.1908(0.6515)$ & $-0.3698(0.7502)$ & $2.0147(1.1080)$ \\
LOG_EDUCATION & $-6.0005(5.2808)$ & $-27.7010(6.6620)$ & $-32.6845(7.9633)$ & $-47.8287(10.7264)$ \\
LOG_HHSIZE & $-15.3499(5.9967)^{* *}$ & $-40.1635(97.7287)$ & $-43.2849(9.0450)$ & $-56.5734(11.5314)$ \\
LOG_AGE & $11.1524(2.5852)^{* * *}$ & $8.231377(2.9832)$ & $9.5998(3.2947)$ & $7.1491(4.5588)$ \\
LOG_EXPERIENCE & $-13.5785(3.7472)^{* * *}$ & $-25.2728(4.9722)$ & $-26.70466(5.8273)$ & $-50.6734(8.6566)$ \\
D_TASTE & $0.2362(0.4560)$ & $0.0045(0.5415)$ & $-0.6089(0.6414)$ & $-0.3325(0.9000)$ \\
D_HEALTHINESS & $-0.7161(0.6567)$ & $-0.8320(0.7909)$ & $-1.4132(0.9199)$ & $0.8912(1.2246)$ \\
D_FRESHNESS & $3.4796(0.7342)^{* * *}$ & $8.0371(0.9919$ & $9.4509(1.1202)$ & $15.7383(1.8146)$ \\
D_FLESHINESS & $0.3666(0.6467)$ & $0.7269(0.7019$ & $1.7080(0.9294)$ & $2.9709(1.5093)$ \\
D_ODOUR & $1.1528(0.4071)^{* * *}$ & $1.0171(0.4723)$ & $1.4116(0.5516)$ & $2.0125(0.8518)$ \\
D_BONE & $-0.0311(0.5217)$ & $-1.7344(0.6466)$ & $-1.9311(0.7528)$ & $-3.4384(1.1030)$ \\
D_EASE PREP & $1.1388(0.4973)^{* * *}$ & $3.8290(0.7082)$ & $2.8529(0.7409)$ & $5.6719(1.1067)$ \\
LOG_PRICE & $64.3331(26.8620)^{* *}$ & $177.5546(34.8488)$ & $176.5736(41.0023)$ & $282.5933(54.9891)$ \\
LOG_INCOME & $1.13129(0.7208)$ & $3.4506(0.8623)$ & $4.6747(1.0498)$ & $10.2877(1.955252)$ \\
LOG_EXPENDITURE & $3.78442(1.6135)^{* *}$ & $9.0856(9.0856)$ & $9.0440(2.4653)$ & $16.7797(3.3677)$ \\
\hline
\end{tabular}

$*$ Note McFadden $\mathrm{R}^{2}=0.4899, \log$ likelihood $=-277.78258, * * *, * *, *$ indicates that estimates are significant at $1 \%, 5 \%$ and $10 \%$, respectively.

Source: Field survey, 2019 figures in parenthesis are S.E $* * * * * *$ sig. at $1 \%, 5 \%$ and $10 \%$ respectively.

Table 3 shows the marginal effects and standard errors estimated from the multinomial logit regression. There are five levels of dependent variables with mudfish being set as the base category to normalize the coefficients of the outcome. The overall percentage correct classification of the MNL models estimated for mudfish, catfish, tilapia, trunk fish and snake-head using SPSS version 25.0 was $63.3 \%$. The overall adequacy of the model was judged by its F-statistics with a value of chi-square (552.91) and a p-value less than one percent. The McFadden's $\mathrm{R}^{2}$ value was 0.50 which indicates that our model has a better fit. Similar to the work of Hausman and McFadden (1984), we tested assumption of independence of irrelevant alternatives (IIA) hypothesis under the null hypothesis that differences in coefficients are not systemic. We obtain a p-value of 0.7618 which indicates that IIA is not violated, suggesting that our model is appropriate for modeling consumer' choice behavior for fresh fish types. 
Table 3. Determinants of consumer choice behaviour for fresh fish types

\begin{tabular}{|c|c|c|c|c|c|}
\hline Model & Mudfish $(\partial y / \partial x)$ & Catfish $(\partial y / \partial x)$ & Tilapia $(\partial y / \partial x)$ & Trunk fish $(\partial y / \partial x)$ & $\begin{array}{r}\text { Snake-head } \\
(\partial y / \partial x) \\
\end{array}$ \\
\hline$\overline{\overline{\text { D_GENDER }}}$ & $0.0547(0.04164)$ & $-0.0542(0.0435)$ & $\begin{array}{c}-0.0430(0.0456) \\
\end{array}$ & $0.0639(0.04134)$ & $-0.0214(0.0256)$ \\
\hline D_MAR STATUS & $-0.0402(0.0466)$ & $0.0671(0.0511)$ & $-0.0183(0.0508)$ & $-0.0675(0.0403)$ & $0.0590(0.0256)^{* *}$ \\
\hline LOG_EDUCATION & $1.3640(0.4339) * * *$ & $0.9210(0.4582) * *$ & $1.4721(0.4945)^{* * *}$ & $-0.7509(0.3873) *$ & $-0.5943(0.2348)^{* *}$ \\
\hline LOG_HHSIZE & $2.3344(0.4593)^{* * *}$ & $0.4843(0.5044)$ & $1.4721(0.4945)^{* * *}$ & $-0.8282(0.4266) *$ & $-0.5183(0.2513)^{* *}$ \\
\hline LOG_AGE & $-0.9677(0.2055) * * *$ & $0.8106(0.202) * * *$ & $0.0599(0.1979)$ & $0.1485(0.1560)$ & $-0.0513(0.1053)$ \\
\hline LOG_EXPERIENCE & $1.7059(0.2794)^{* * *}$ & $-0.1145(0.3087)$ & $-2.8367(0.8907)$ & $-0.2463(0.2789)$ & $-0.7659(0.1872) * * *$ \\
\hline D_TASTE & $-0.0082(0.0398)$ & $0.0371(0.0434)$ & $0.0195(0.4362)$ & $-0.0450(0.0355)$ & $-0.0033(0.0220)$ \\
\hline D_HEALTHINESS & $0.0767(0.0570)$ & $-0.0319(0.0620)$ & $-0.0287(0.0611)$ & $-0.0728(0.0491)$ & $0.0567(0.0270)$ \\
\hline D_FRESHNESS & $-0.5011(0.0356)^{* * *}$ & $-0.0732(0.0347)^{* *}$ & $0.1843(0.0375)^{* * *}$ & $0.1666(0.03037)^{* * *}$ & $0.2234(0.0277)^{* * *}$ \\
\hline D_FLESHINESS & $-0.0574(0.0541)$ & $-0.0177(0.0633)$ & $-0.0398(0.0575)$ & $0.0593(0.0549)$ & $0.0557(0.0379)$ \\
\hline D_ODOUR & $-0.1086(0.0334) * * *$ & $0.0683(0.0367)^{*}$ & $-0.0100(0.0363)$ & $0.0247(0.0210)$ & $0.0016(0.0019)$ \\
\hline D_BONE & $0.0636(0.0453)$ & $0.0961(0.0479) * *$ & $-0.0685(0.0486)$ & $-0.0388(0.0396)$ & $-0.0523(0.0257)^{* *}$ \\
\hline D_EASE PREP & $-0.1904(0.0389) * * *$ & $-0.0636(0.0436)$ & $0.1943(0.0487)^{* * *}$ & $-0.0131(0.0335)$ & $0.0730(0.0233)^{* * *}$ \\
\hline LOG_PRICE & $-9.9732(2.1014)^{* * *}$ & $-2.3847(2.24113)$ & $6.6819(2.2777)^{* * *}$ & $3.4243(1.2055)^{* * *}$ & $0.2659(0.2721)$ \\
\hline LOG_INCOME & $-0.2006(0.0582) * * *$ & $-0.0906(0.0616)$ & $0.0158(0.0618)$ & $0.0821(0.0544)$ & $0.1933(0.0433)^{* * *}$ \\
\hline LOG_EXPENDITURE & $-0.5410(0.1351)^{* * *}$ & $-0.0715(0.1432)$ & $0.2890(0.1500)^{*}$ & $0.0814(0.1221)$ & $0.2421(0.0708)^{* * *}$ \\
\hline
\end{tabular}

\section{Mudfish model}

Table 3 shows that consumption of mudfish is influenced by both socio-economic of the respondents and fish-specific attributes. The choice of mudfish is reduced by the following variables as freshness, fleshy fish, odour and easy to prepare at $1 \%$ probability level of significance. That is, a unit change in any of these variables, consumers will be less likely to purchase mudfish compared to non-freshness, nonfleshy fish, odorous fish and not easy to prepare. In the like manner, results show that increase in the average price of fresh fish, household expenditure on fish, consumer's experience, household income and age variables will significantly decrease the purchase of mudfish, thus indicating that a $1 \%$ increase in these variables does not translate into increased consumption of mudfish but will rather decrease its choice from the food basket. Similar result was found by George et al. (2017) for willingness to pay for fish attributes in Vietnam.

The negative coefficient of household income variable shows that a large number of consumers spend less of their income on fresh fish as income increases in the study area. The result, however, differs from the finding of Abdullahi et al. (2011) that found direct relationship between income and consumer behaviour for fresh fish in Malaysia. Also, a $1 \%$ increase in the price of mudfish will cause a consumer to lower his /her demands for mudfish by 10 per cent. However, education of household and number of household members had positive and significant influence on the choice of mudfish at 5 per cent level. Abdullahi et al (2011) reported similar result for effect of household size of fresh fish in Malaysia. Increasing these variables at $1 \%$ will make consumers to be more likely to choose mud fish by 36 and 33 per cent, respectively.

\section{Catfish model}

The probability of choosing catfish from the food basket decreases with freshness of the fish significantly at the 5 per cent level. However, good odour and less bony fish increase the probability of consumption of catfish in the fresh fish food basket in the study area compared to bad odour and bony fresh fish types. The results also indicate that the age of the respondent and education of household head increase with the probability of the choice of catfish significantly and consistently at the one and 5 per cent levels, respectively. As a matter of fact, addition of one year to the age of the respondents provides him/her the opportunity to weigh the benefit of eating or not 
eating fresh fish. Likewise consumers who are educated will have a better understanding than uneducated consumers. It also afford consumer to consider those qualities in fish like Omega-3 compared to red meat.

\section{Tilapia model}

In tilapia model, result reveals that freshness and easy to prepare variables are positively significantly related to the probability of choosing tilapia fish at the one per cent compared with a non-freshness and not easy to prepare fish. Also, the marginal effect of price of fish on the consumption of tilapia was not consistent with the theoretical expectation. Intuitively, consumer choice behaviour for fresh fish in the study area is associated with strong preference and habit. The probability of purchasing tilapia fish increases with a unit price increase by 6.6\%. Further scrutiny of the results show that expenditure of household head on fresh fish had direct impact with the choice of tilapia category but this however decreases with the education of the household head and household size. The finding on education of the household head as well as household size of the respondent is consistent with the earlier work done by Solomie et al. (2015) on consumer preference and willingness to pay for farmed in treated wastewater in Ghana.

\section{Trunk fish model}

The demand for the choice of trunk fish increases significantly and consistently with the freshness variable at the one per cent level compared to non-freshness. For the average price of fresh fish, the decision to purchase trunk fish also increases by a one unit increase in price but decreases with education of the household head and household size. Education of a consumer will be of good help to understand and process empirical information reported on nutritional values of food like fresh fish types and then takes decision. On the other hand, large household size may decide to buy less of trunk fish if income is low couple with high price of fresh fish.

\section{Snakehead fish model}

For the snakehead fish model, results obtained show that probability of demand for snake-head fish type increases with the following freshness, ease to prepare, income of household head, expenditure on fresh fish and marital status. The variables are positively and statistically significant at the probability level of 1 and 5 per cent, accordingly. It also implies that consumers are more likely to buy snake-head fish compared with fish that are not fresh or ease to prepare. A one unit increase in income variable indicates that the probability of purchasing fresh fish from the food basket favours snake-head fish, ceteris paribus. The result here is theoretically consistent with the law of demand. However, bony fish, experience in the consumption of fish and education of the respondent decrease with the probability of choosing snakehead fish. This suggests that consumers will be less likely to choose snake-head fish, if there is aone unit increase in any of the variables, holding other explanatory variables constant. People with less education are less likely to select snake-head because of lack of awareness and knowledge about the health benefits that can be derived from snakehead.

\section{CONCLUSIONS AND RECOMMENDATIONS}

\section{Conclusions}

The study was carried out to investigate underlying factors affecting consumers' choice behaviour for fresh fish types in Nigeria. Specifically, the study described the 
socioeconomic characteristics of consumers and identified factors affecting the choice of consumers for fresh fish type (e.g. cat fish, mudfish, tilapia, trunk fish and snake head).

A multi stage sampling procedure was used to select 360 household heads in the study area being one of the major fishing grounds in Nigeria. A structured questionnaire was used to retrieve pertinent information on socio-economic variables and fish-specific attributes. Descriptive statistics such as table, mean and standard deviation were used to summarize the socio-economic characteristics of the consumers and inferential statistics such as multinomial logit model was used to identify factors determining consumers' choice behaviour for fresh fish types in the study area.

Most (81 percent) of the household heads were females. The mean age of household heads was 35 years with an average household size of 4 members while the mean years of schooling was 13 years. Results further showed that majority of the consumers sampled were married, 73.0 percent purchased fish due to easy preparation, 56.0 percent desired fish without odour, 74.0 percent of consumers purchased fresh fish on health ground while 42.0 percent of the consumers considered freshness of the fish as a pre-condition to purchase fish while 74 percent of household heads based purchases on good taste. The study revealed that the average price of fresh fishes was $\$ 710.0$ (US\$1.97) and monthly mean expenditure on fresh fish was $\$ 3,611.94$ (US\$10.12).

The study further showed that education and number of household members determine the choice of mudfish. For catfish, the study concluded that improvement on fish odour, bone, education and age will motivate consumers to buy catfish. For the snakehead fish model, results obtained show that probability of selecting snake-head fish type increases with the following variables freshness, ease to prepare, income of household head, expenditure on fresh fish and marital status while bony fish, consumption experience and education of the respondent are likely to decrease with the probability of choosing snakehead fish. People with less education are less likely to buy snake-head fish because of lack of awareness and knowledge about the health benefits that can be derived from it. The study also concluded that the decision to purchase trunk fish also increases by an increase in fish price but decreases with education of the household head and household size.

\section{Recommendations}

Based on the findings in this study, it is recommended that government should encourage fish farmers to grow more of fresh fish category presented in this study through aquaculture for local consumption and if possible for export. The result also suggests that government and private sector should provide research funding that stimulates researches on genetic manipulation of these fish categories to reduce fish odour and gain more flesh. To keep fish fresh always, provision of storage facilities should also be provided to avoid unnecessary wastage. Policies on consumer protection that lays emphasis on fish quality, education and health should be strengthened in the country.

\section{REFERENCES}

Abdullahi, F. A., Zainalabidin, M. \& Mohd, M. I. (2011). Determinants of Fresh Fishpurchasingbehaviour among Malaysian Consumers. Current Research Journal of Social Sciences 3(2), 126-131.

Adeola, A. A Ayegbokiki, A. O, A kerele, D, Adeniyi, B. T \& Bamidele, N. A. (2016). Marketing Perspective of Smoked Catfish by Consumers in Southwest, Nigeria. Applied Tropical Agriculture, 21(2), 58-66 
Azabagaoglu, M., Abdikokoglu, O. D. I. \& Unakitan, G. (2016). Consumer's Fish Purchase Behaviour in Tekitdag. Journal of Tekirdag Agricultural Faculty, 13(04), 145-151.

Bateman, J. Carson, R. T., Day, B., Hanemann, W. M., Hanley, N., Hett, H., Lee, M. J., Loomes, G., Mourato, S., Özdemiroglu, E., Pearce,W. D. \& Elgar, E. (2002). Economic valuation with Stated Preference Techniques: A Manual, Edward Elgar Publishing, Inc.

Bonface, N., Emmanuel, K. \& Sloans, C. (2017). The Demand for Fish Products in Malawi: An Almost Ideal Demand System Estimation: Journal of Economics and Sustainable Development, 8(16), 63-71

Can, M. F., Gunlu, A. \& Can, H. Y. (2015). Fish Consumption Preferences and Factors Influencing it. Food sci. Technology, Campinas, 35(2), 339-346. DOI: http://dx.doi.org/101590/1678-457x.6624.

CIA World Factbook, (2014): http://www.factfish.com/country/Nigeria

Emefiele, G. (2019). Fisheries committee for the West Central Gulf of Guinea. Available at: https://www.vanguardngr.com/2019/09/nigeria-spends-1-2bn-toimport-fish-annually-emefiele.

Fishery and Aquaculture Country Profile, Nigeria. (2007). Country Profile Fact Sheets. In: FAO Fisheries and Aquaculture Department (Online) Rome Updated 1 November 2017 Available at: http://www.fao.org/fishery/

George, K. D. Miriam, O., Nguyen, D. L. \& Ganesha, M. (2017). Households' Willingness to Pay for Fish Product Attributes and Implications for Market Feasibility of Wastewater-Based Aquaculture businesses in Hanoi, Vietnam. Resource, 6, 30. DOI: http://doi.10.3390/resources6030030

Greene, W. H. (2003). Econometric Analysis Fifth Edition, Pearson Education International Upper Saddle River, New Jersey.

Hausman, J. A \& McFadden, D. L. (1984). Specification Tests for the Multinomial Logit Model Econometrica 52: 1219-1240

Jimoh, W. A., Popoola M. A., Ibeahim, G. A., Ayeloja, A .A., Ayanwale, A. O. S \& Akinosho, G. A (2013) Evaluation of consumers' preference for Fresh and Frozen Fish Products in Ibadan metropolis, Nigeria. PAT, 9(1) 13-20

Kreider, C. K., Gempesaw, C. M., Bacon, J. R., Toensmeyer, U. C \& Groff, A. J. (1993). An Analysis of Consumer Perceptions of Fresh Fish and Seafood in the Delmarva Region, Journal of food distribution research, 24(2), 37-48.

Moses, J. D., Daniel, A. D, Giroh, D. Y., Zalkuwi, J. \& Akindele, O. (2015). The Influence of Socio-Economic Characteristics on Consumers' Preference on Fish Purchase in Yola North Local Government Area, Adamawa. International Journal of Environmental and Agricultural Research, 1(7), 1-11

National Population Commission (2006). Official Gazette (FGP/71/52007/2,500(OL24). Legal Notice on Publication of the Details of the Breakdown of the National and State Provisional Totals 2006 Census, Available at: http://www.nigerianstate.gov.ng.

Nauman, F. A., Gempesaw, C. M., Bacon, J. R \& Manalo, A. (1995). Consumer Choice for Fresh Fish Factors Affecting Purchase Decisions. Marine Resource Economics, 10, 117-142.

Owusu-Sekyere, E. (2014). Consumer Preferences and Willingness to Pay for Beef Attributes in Ghana. M.sc Thesis in Agricultural Economics, Faculty of Natural and Agricultural Sciences, Department of Agricultural Economics, University of the Free State. Bloemfontein 
Qiujie, Z. 1, H. Holly, W. \& Yonggang. L. (2018). Consumer Purchase Intentions for Sustainable Wild Salmon in the Chinese Market and Implications for Agribusiness Decisions. Sustainability 10(5), 1-16.

Ratliff, E. A. (2017). Factors Influencing Consumer Preferences for Tangible and Intangible Seafood Characteristics and Community Supported Fishery Marketing Outlets, All Theses 2772. Available at: http://tigerprints.clemson.edu/all theses/2772.

Solomie, A. G, Amewu, S \& Philip, A. (2015). Consumer Preference and Willingness to Pay for Farmed in Treated Wastewater in Ghana. Selected Paper Prepared for Presentation at the 2015 AAAEA\& WAEA Joint Annual Meeting, San Francisco California, 26-28 July 2015.

World Fish, (2018). World Fish Nigeria Strategy 2018-2022 Penang Malaysia.

World Bank, (2018) . Annual Population Growth, Nigeria World Bank Data. Available at: data.worldbank.org 